\title{
Application of E-Commerce Interactive Marketing Model Based on Distributed Algorithm of Mobile Ad Hoc Network
}

\author{
Xuehui Jiang \\ College of Information Engineering, Zhengzhou University of Industrial Technology, Xinzheng 451150, China \\ Correspondence should be addressed to Xuehui Jiang; 002664@zzgyxy.edu.cn
}

Received 29 September 2021; Revised 18 October 2021; Accepted 27 October 2021; Published 2 December 2021

Academic Editor: Deepak Kumar Jain

Copyright @ 2021 Xuehui Jiang. This is an open access article distributed under the Creative Commons Attribution License, which permits unrestricted use, distribution, and reproduction in any medium, provided the original work is properly cited.

\begin{abstract}
With the development of the mobile Internet, e-commerce has become one of the important ways of daily consumption, but how to effectively use e-commerce for interactive marketing and increase sales is an important research direction. Mobile ad hoc distributed algorithms are introduced in this paper. Through sorting out the mode of e-commerce interaction influence, process marketing is performed from two-dimensional code, short message, business district, mobile search, Bluetooth, wireless network, and other methods, and interactive marketing is tried in various industries such as education, tourism, agriculture, catering, finance, and publishing, and simulation experiments are used to verify them. The simulation experiment results show that the mobile ad hoc distributed algorithms are effective and can support the e-commerce interactive marketing model.
\end{abstract}

\section{Introduction}

With the continuous development of the mobile Internet, the information age has come. Under the background of the development of this era, companies must strengthen communication and contact with consumers and treat consumers' demands as the first priority, provide products and services that consumers need, and gain the favor of consumers in a short time in order to conduct marketing propagation better, and the emergence of mobile ecommerce can better solve the above problems $[1,2]$. Mobile e-commerce is a representative product developed at the level of modern informatization. It can design and establish a relevant network platform with the help of the Internet to further meet customers' requirements [3-5]. It should be noted that, on the one hand, e-commerce can promote consumption and change the consumption scene. For example, during living with family due to the epidemic, you can still carry out online consumption and order the takeaway through e-commerce; on the other hand, different from traditional offline consumption, e-commerce can facilitate more personalized and demand-oriented push for consumer psychology. For modern consumption scenarios, more attention should be paid to the interaction between consumers and enterprises, to accurately understand consumers' consumption habits and consumer psychology, to promote enterprises to produce more products that meet consumer needs, and to further establish good communication environment to win the trust of consumers [6-8]. For example, the live broadcasts conducted by major e-commerce companies build the connection between consumers and products and establish a communication platform to generate interactions through the anchor, to further realize the effective marketing of enterprises [9].

The emergence and improvement of intelligent terminals and $5 \mathrm{G}$ networks have further promoted the development of e-commerce. Consumers can carry out e-commerce through mobile terminals at any time, without the need for PC [10]. Different from e-commerce, mobile e-commerce relies on mobile communication networks, combines with the traditional Internet, and carries out various e-commerce activities and through mobile terminals [11]. But it is important that the limitations of e-commerce interactive marketing still need to be resolved. The mobile ad hoc distributed algorithms are introduced in this paper, analyzing its applicability in different industries through combining e-commerce interactive marketing models, and proposed corresponding interactive marketing methods. Verified by simulation, it is aimed at increasing the sales volume of e-commerce marketing and 
promoting the orderly, healthy, and steady development of the economy.

\section{E-Commerce Interactive Marketing}

2.1. The Meaning of Mobile E-Commerce Interactive Marketing. The interactive marketing of e-commerce is an interactive behavior between consumers and enterprises, different from mobile e-commerce interactive marketing. Through mobile smart terminals as the carrier, it conducts interactive marketing through $5 \mathrm{G}$ communication. In addition, the consumer's own autonomy and enthusiasm cannot be ignored, which is the autonomous behavior of ecommerce according to one's own needs.

However, it cannot be ignored that due to the difference from traditional Internet e-commerce, e-commerce on mobile terminals is usually different from e-commerce in equipment, network, and application scenarios. Mobile ecommerce can more reflect immediacy, interactivity, and personalization in an interactive marketing mode. It emphasizes the characteristics of accuracy, orientation, and mass decentralization. In particular, it also has the timeliness of the information brought about by push, the low cost, and the wide audience, such as Pinduoduo and other new types of interactive mobile and e-commerce [12-15].

2.2. Prerequisites for Successful Implementation and Principles for Success. First is the prerequisite for successful implementation. Mobile e-commerce needs to be recognized by both consumers and enterprises, and meanwhile, products need to reach a certain quality, so that enterprises can communicate with consumers well and ensure that consumers have a better e-commerce shopping experience [16, 17]. In addition, interactive marketing activities need to be recognized by consumers, rather than passively accepted.

Second is the corresponding principles for success. In the mobile commerce environment, if interactive marketing activities are required, it is necessary to clarify the principles and acceptance methods of individualization according to different users, instead of interacting in the form of bundled sales, which is extremely easy to cause disgust $[18,19]$.

\section{Mobile Ad Hoc Network Distributed Algorithm}

For the mobile ad hoc network distributed algorithm, it is first necessary to set up an acentric multihop network. Because the time reference of each network node is not uniform, the initial time of the specific node state cannot be measured by time, and the time correction cannot be performed. Each node can only obtain the time deviation of neighboring nodes around it, to correct its own time by such method.

Specifically, as shown in Figure 1, taking node 5 as an example, it can only sense the reference time deviation of neighboring nodes and realize the time correction of neighboring nodes through the nodes, specifically as shown in

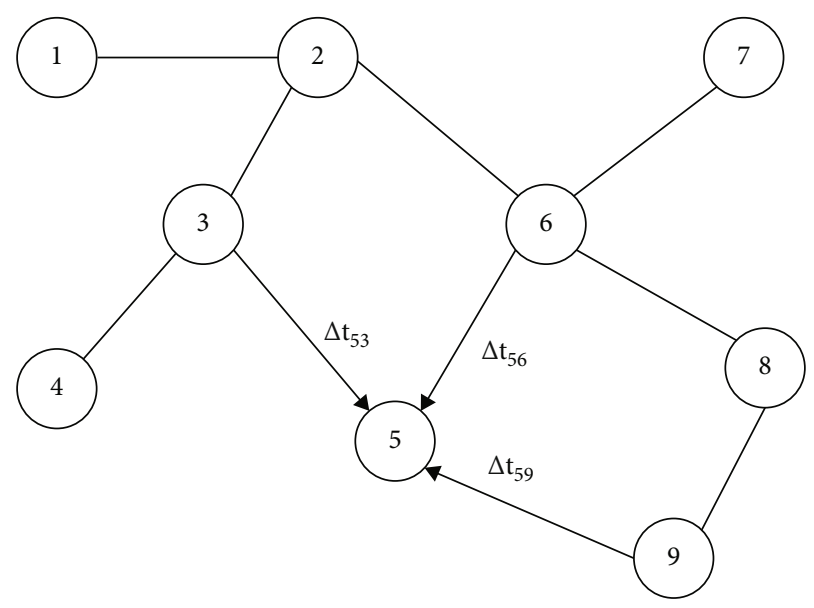

Figure 1: The mutual synchronization process of nodes.

$$
\varepsilon_{s}(n)=w_{55} \cdot 0+w_{53} \Delta t_{53}(n)+w_{56} \Delta t_{56}(n)+w_{59} \Delta t_{59}(n) .
$$

In the formula, $w_{55}+w_{53}+w_{56}+w_{59}=w$.

Based on the calculation of formula (1), adjust your own reference time according to the corresponding time, as shown in

$$
t_{5}(n+1)=t_{5}(n)-\varepsilon_{5}(n)
$$

In order to further analyze the algorithm, the time correction can be averaged, and the specific calculation can be carried out by

$$
\varepsilon_{i}(n)=\sum_{k=1}^{N} w_{k} \Delta t_{i k}(n) .
$$

Among them, the number of network nodes is denoted by $N$, and the deviation of neighboring nodes is averaged as a time correction, specifically as shown in

$w_{i j}= \begin{cases}\frac{1}{d_{i}+1}, & \text { when node } i \text { and node } j \text { are connected, } \\ \frac{1}{d_{i}+1}, & i=j, \\ 0, & \text { when node } i \text { and node } j \text { are not connected, }\end{cases}$

where $d_{i}$ is the connectivity of node $i$.

Use this weighted average $\varepsilon_{i}$ to correct the local reference time base, as shown in

$$
t_{i}(n+1)=t_{i}(n)-\varepsilon_{i}(n) .
$$

In the ad hoc network, because there is no unified time reference, relative to the fixed virtual time, the corresponding time state can be set, as shown in Figure 2. 


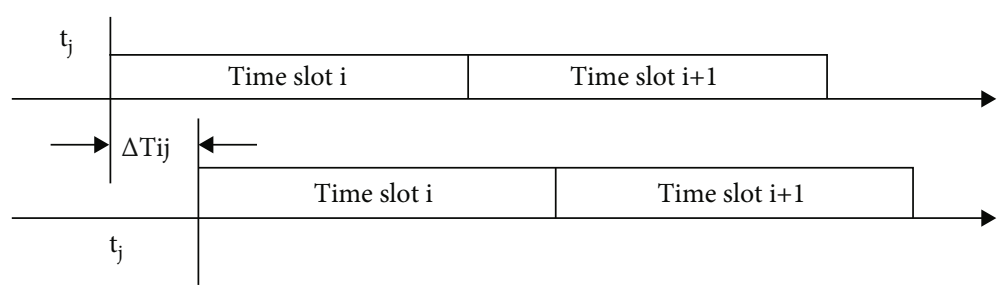

FIgURE 2: Time slot deviation of two nodes.

Formula (6) can be used for calculation:

$$
\Delta t_{i j}(n)=t_{i}(n)-t_{j}(n)
$$

The reference time base after the $n$th revision of node $i$ is calculated by

$$
\begin{aligned}
t_{i}(n+1) & =t_{i}(n)-\varepsilon_{i}(n)=t_{i}(n)-\sum_{j=1}^{N} w_{i j} \Delta t_{i j}(n) \\
& =t_{i}(n)-\sum_{j=1}^{N} w_{i j}\left(t_{i}(n)-t_{j}(n)\right)=\sum_{j=1}^{N} w_{i j} t_{j}(n) .
\end{aligned}
$$

In the formula, $\sum_{j=1}^{N} w_{i j}=1$.

Assume

$$
\begin{aligned}
& T(n)=\left[\begin{array}{c}
t_{1}(n) \\
t_{2}(n) \\
\vdots \\
t_{i}(n) \\
\vdots \\
t_{N}(n)
\end{array}\right] \\
& W=\left[\begin{array}{cccccc}
w_{11} & w_{12} & \cdots & w_{1 j} & \cdots & w_{1 N} \\
w_{21} & w_{22} & \cdots & w_{2 j} & \cdots & w_{2 N} \\
\vdots & \vdots & \cdots & \vdots & \cdots & \vdots \\
w_{i 1} & w_{i 2} & \cdots & w_{i j} & \cdots & w_{\mathrm{iN}} \\
\vdots & \vdots & \cdots & \vdots & \cdots & \vdots \\
w_{N 1} & w_{N 2} & \cdots & w_{N j} & \cdots & w_{N N}
\end{array}\right] .
\end{aligned}
$$

Then,

$$
T(n+1)=W \cdot T(n)=W^{k+1} \cdot T(0) .
$$

The weight relationship between each node can be represented by a directed graph.

Lemma 1. The necessary and sufficient condition for directed graph $G$ to be a strongly connected graph is that the adjacency matrix of graph $G$ is the primitive matrix.
Lemma 2. The necessary and sufficient condition for a nonnegative matrix $A$ to be a primitive matrix is that there is at least one positive integer $m$ such that $A^{m}>0$.

Theorem 3. For a fully connected network, there is always an integer $m$ greater than 0 , so any element in $W$ is greater than 0 .

Proof. For a fully connected network, there is always a path from any node $i$ to any node $j(i \neq j)$ in the network. In the weighted directed graph corresponding to the network, any two vertices are also reachable; that is, the weighted directed graph corresponding to the fully connected network is a strongly connected graph. From Lemma 1, we can see that the adjacency matrix $W$ corresponding to the weighted directed graph is a primitive matrix.

And because the weight matrix $W$ is a nonnegative matrix, from Lemma 2, there is a positive integer $m$, which makes $W^{m}>0$.

The geometric meaning of $m$ is the minimum number of hops between any two nodes in the network. We call $m$ the minimum number of hops in the network. Obviously, $m \leq$ $N-1, N$ is the number of nodes in the network.

Theorem 4. In a network of $N$ ( $N$ is a positive integer and $N \geq 2$ ) nodes, each node $i$ corrects its own time reference with the weighted average of the time reference deviation $\Delta t_{i j}$ of its neighboring node j; then finally, the network-wide time reference converges to the same value.

Proof. Let the initial time reference set of the nodes of the entire network be

$$
\left\{t_{1}(0), t_{2}(0), \cdots, t_{N}(0)\right\}, \quad t_{i} \geq 0 .
$$

After the $n$th iteration,

$$
\begin{aligned}
& a(n)=\min \left\{t_{1}(n), t_{2}(n), \cdots, t_{N}(n)\right\}, \\
& b(n)=\max \left\{t_{1}(n), t_{2}(n), \cdots, t_{N}(n)\right\} .
\end{aligned}
$$

Obviously,

$$
a(n) \leq b(n)
$$


After weighted average, we can get

$$
t_{i}(n+1)=\sum_{j=1}^{N} w_{i j} t_{j}(n) \geq \sum_{j=1}^{N} w_{i j} a(n)=a(n) .
$$

It holds for all $i$, including the maximum value $a(n+1)$ of $t_{i}(n+1)$, so

$$
a(n+1) \geq a(n)
$$

It shows that the minimum value increases with the increase of $n$. In the same way, it can be proved that the maximum value decreases with $n$ increases:

$$
\begin{aligned}
& t_{i}(n+1)=\sum_{j=1}^{N} w_{i j} t_{j}(n) \leq \sum_{j=1}^{N} w_{i j} b(n)=b(n), \\
& b(n+1) \leq b(n) .
\end{aligned}
$$

Since both $a(n)$ and $b(n)$ are bounded sequences, when $n \longrightarrow \infty$, both $a(n)$ and $b(n)$ tend to their limits. Next, prove that these two sequences tend to the same limit.

(1) If $m=1$

Suppose that after $n$ iterations, $t_{p}(m)$ reaches minimum value $a(n)$, and $t_{q}(n)$ reaches the maximum value $b(n)$. After $n+1$ iterations, $t_{r}(n+1)$ reaches the minimum value $a(n$ $+1)$, and $t_{s}(n+1)$ reaches the maximum value $b(n+1)$. Specifically, it can be calculated by

$$
\begin{aligned}
a(n+1) & =t_{r}(n+1)=\sum_{k=1}^{N} w_{r k} \cdot t_{k}(n) \\
& =\varepsilon \cdot t_{q}(n)+\left(w_{r q}-\varepsilon\right) \cdot t_{q}(n)+\sum_{k=1, k \neq q}^{N} w_{r k} \cdot t_{k}(n) .
\end{aligned}
$$

Because $w_{i j}>0$, there is always an arbitrarily small positive real number $\varepsilon$; it can be calculated by

$$
\left(w_{r q}-\varepsilon\right)>0
$$

So, it can be calculated by

$$
\begin{aligned}
a(n+1) & \geq \varepsilon \cdot b(n)+\left(w_{r q}-\varepsilon+\sum_{k=1, k \neq q}^{N} w_{r k}\right) \cdot a(n) \\
& =\varepsilon \cdot b(n)+(1-\varepsilon) \cdot a(n) .
\end{aligned}
$$

In a similar way, it can be calculated by

$$
\begin{aligned}
b(n+1) & =t_{s}(n+1)=\sum_{k=1}^{N} w_{s k} \cdot t_{k}(n) \\
& =\varepsilon \cdot a(n)+\left(w_{s p}-\varepsilon\right) \cdot t_{p}(n)+\sum_{k=1, k \neq p}^{N} w_{s k} \cdot s_{k}(n) \\
& \leq \varepsilon \cdot a(n)+\left(w_{s p}-\varepsilon+\sum_{k=1, k \neq p}^{N} w_{s k}\right) \cdot b(n) \\
& =\varepsilon \cdot a(n)+(1-\varepsilon) \cdot b(n) .
\end{aligned}
$$

Based on subtracting the two formulas from each other, it can be obtained as shown in

$$
\begin{aligned}
b(n+1)-a(n+1) & =(1-2 \varepsilon) \cdot[b(n)-a(n)] \\
& =(1-2 \varepsilon)^{n+1} \cdot[b(0)-a(0)] .
\end{aligned}
$$

Therefore, when $n \longrightarrow \infty,[b(n+1)-a(n+1)] \longrightarrow 0$; that is, $a(n)$ and $b(n)$ tend to the same limit.

Therefore, when $n \longrightarrow \infty, t(n) \longrightarrow t^{*}$.

(2) If $m>1$

$W^{m}$ represents the power of $m$ of $W$, and $w_{i j}^{(m)}$ represents the elements in row $i$ and column $j$ of $W^{m}$.

(i) If $n=k m$

$$
t(n)=t(k m)=\sum_{j=1}^{N} w_{i j}^{(m)} t_{j}((k-1) m) .
$$

Same as (1), when $k \longrightarrow \infty, t(n)=t(k m) \longrightarrow t^{*}$.

Namely, $n \longrightarrow \infty$ 时, $t(n) \longrightarrow t^{*}$.

(ii) If $n \neq k m$

Suppose $s=1,2,3, \cdots, m-1, n=k m+s$, then

$$
t(n)=t(k m+s)=\sum_{j=1}^{N} w_{i j}^{(s)} t_{j}(k m) .
$$

When, $k \longrightarrow \infty$; therefore, $t(n)=t(k m) \longrightarrow t^{*}$,

$$
t(n)=\sum_{j=1}^{N} w_{i j}^{(s)} t^{*}=t^{*}
$$

Namely, $n \longrightarrow \infty, t(n) \longrightarrow t^{*}$.

Proof is completed.

After $n$ iterations, all $t_{i}(n)$ converge to neighborhoods with the same fixed value.

In theory, each node sends a data packet in its own initial reference time slot. After receiving this data packet, other nodes compare with the local reference time slot benchmark 
to calculate the reference time slot deviation of the two nodes. However, since wireless signals propagate in free space through electromagnetic waves, there is a time delay, so the time delay deviation calculated in this way includes the transmission time delay of the signal in the wireless channel. The calculation method of time slot deviation to eliminate signal propagation delay is discussed below.

In a symmetrical channel network, it is assumed that any two nodes $i$ and $j$ in the network have an initial reference time base; the reference time base deviation is $\Delta t$; without loss of generality, it is assumed that the reference time base of node $i$ is ahead of node $j\left(\Delta t_{i j}=-\Delta t_{j i}=-\Delta t\right)$, the propagation delay between the two nodes is $\Delta T$, and each node sends a piece of data on its own reference time basis.

Assuming that the time slot period is $T_{s}$, the relationship between the reference time deviation $\Delta t_{i j}$ and the propagation time delay $\Delta T$ is shown in

$$
\delta_{i j} \bmod \left(T_{s}\right)=\Delta T+\Delta t_{i j}=\Delta T-\Delta t .
$$

Node $j$ also sends a data packet according to its own reference time base, and the time delay value $\delta_{j i}$ is shown in

$$
\delta_{j i} \bmod \left(T_{s}\right)=\Delta T+\Delta t_{j i}=\Delta T+\Delta t .
$$

Calculate the reference time deviation $\Delta t$ between the two nodes, as shown in

$$
\begin{aligned}
\Delta t_{i j} & =\frac{\left(\delta_{i j}-\delta_{j i}\right) \bmod \left(T_{s}\right)}{2}, \\
\Delta t_{j i} & =\frac{\left(\delta_{j i}-\delta_{i j}\right) \bmod \left(T_{s}\right)}{2} .
\end{aligned}
$$

\section{Mobile E-Commerce Interactive Marketing Model}

4.1. Main Mode. At present, there are many mobile ecommerce interactive marketing modes, which can mainly include two-dimensional code, short message, mobile friend circle, search, Bluetooth push, wireless network, mobile community section, Weibo, and other new media [20].

4.1.1. Mobile QR Code. The mobile QR code is a way to recognize images. It is based on new media, but unlike traditional print media, it achieves integration and intercommunication with network media. This method greatly facilitates direct communication between consumers and enterprises, improves the interaction between enterprises and audiences, breaks through traditional restrictions, and truly realizes real-time interaction between consumers and enterprises.

4.1.2. SMS URL. The corresponding short message is used to push the URL, and the mobile terminal is used for WAP access. Enterprises can display products online through the website, and users can query online according to their needs. The combination and integration can effectively connect enterprises and consumers, reduce the cost of advertising and publicity of enterprises, and provide enterprises with more opportunities for market development and product promotion.

4.1.3. Mobile Commercial Circle. The mobile business circle is a large-scale movement. In this mode of operation, ordinary users, businesses, operators, etc., can be integrated. On the one hand, merchants can achieve the convergence and important play of brand influence; on the other hand, they can also provide precise services for users.

4.1.4. Mobile Search. Mobile search means that consumers use mobile phones and other participating terminal devices to search through multiple access methods such as short messages, wireless application protocols, and interactive voice responses to obtain website information, mobile value-added service content, and local service data. It can provide personalized, regional, and intelligent information search based on the needs and characteristics of mobile users.

Mobile search can be displayed according to the location of the user's terminal, and through close integration with mobile positioning services, it can provide users with more targeted products. In the search method, several methods such as WAP search, SMS search, and voice search are mainly used. WAP search supports WEB browsing on advanced terminals. Therefore, this method has a better user experience. SMS search is not conducive to user experience. Voice search is a combination of voice recognition technology and mobile phone search. It is in line with user habits and is convenient and quick to use, but the technology is still not mature enough. The interactive mode of mobile search mainly refers to that when consumers use mobile terminals to conduct related searches, they can obtain WEB and WAP site information, enter the enterprise site, and complete the interaction with the enterprise.

4.1.5. Bluetooth Interaction. Bluetooth technology can be used to form an interaction between merchants and consumers, shorten the spatial distance between the two, and shorten the time period of marketing methods and purchase behavior.

4.1.6. Wireless Website. Wireless websites are also called mobile websites, which mainly refer to WAP websites built by enterprises (including mobile websites with .mobi domain names) and WAP websites created by well-known companies (such as Monternet). Enterprises can use their own WAP websites to interact with consumers, but consumers are reluctant to enter the wireless address in the mobile browser because the domain name of the wireless address is difficult to remember. And companies use WAP websites created by well-known companies; through WAP push technology, the company's information will be actively pushed to consumers' mobile phones, to achieve interactive communication with consumers. Many well-known brand companies around the world have created mobile websites with .mobi domain names, successfully providing customers with a more intuitive mobile experience. 
Many new interactive marketing application models based on mobile e-commerce technology and platforms, such as mobile communities and mobile microblogs, have also emerged. The mechanism of these new forms of interactive processes has not fundamentally changed, and they are leading the continuous innovation of enterprise mobile ecommerce interactive marketing application models.

\subsection{Application of Mobile E-Commerce Interactive Marketing Model in Different Industries}

4.2.1. Education and Training Industry. The application of mobile e-commerce in the education industry is different from other mobile e-commerce activities, and its activities must follow the laws of the education industry. Therefore, mobile e-commerce applications in the education industry have limited their business content, which is to provide content services for the education industry and provide value added for consumers who want to learn or receive education.

4.2.2. Tourism Industry. Travel marketing based on mobile e-commerce is the fastest marketing method, which can provide the fastest and most extensive personalized, self-service travel services and finally realize a series of innovative travel marketing activities.

4.2.3. Agriculture. The application of the mobile e-commerce interactive marketing model in agriculture not only makes the spread of agricultural product development and agricultural product supply and marketing information wider and provides better services but also brings better opportunities for the production and sales of agricultural products in various regions. Among them, in the agricultural product mobile e-commerce application, other service items such as information service, map query, and agricultural product voice service can be added.

4.2.4. Catering Service Industry. Using the mobile ecommerce interactive marketing platform, through the integration of mobile Internet media and other media, it can provide the most interactive solutions for restaurant chains, catering services, gourmet operations, catering group purchases, and food orderers.

4.2.5. Financial Industry. At present, there are more and more companies in the market that use mobile terminals to engage in stock trading and insurance business. For example, securities companies provide customers with mobile stock trading services and use mobile e-commerce interactive marketing platforms to provide customers with realtime information and order transactions, which is greatly convenient. By improving customers, customer satisfaction can be increased, so that the number of customer groups can be expanded, the scope of business can be expanded, and performance can be improved.

4.2.6. Publication. A mobile multimedia publishing platform based on QR codes built by traditional publishing companies and network media has emerged. The integration of advantages of traditional publishing and online publishing is the

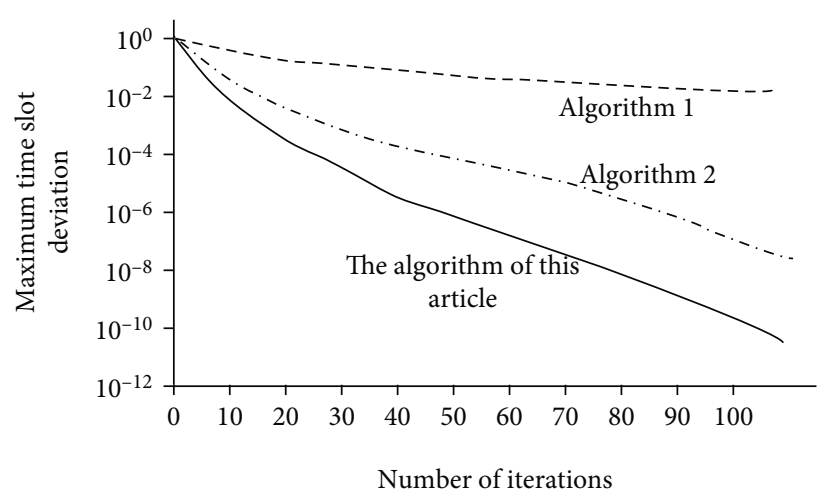

FIgURE 3: The relationship between the normalized time slot deviation and the number of iterations.

general trend and will be accelerated. QR code is becoming the "intermediary" force in this round of integration and publishing with its advantages of convenience, large amount of information, and market monitoring, a new weapon in the development of industry marketing.

With the maturity and development of mobile ecommerce technology and platforms, interactive marketing models under the mobile Internet environment will continue to innovate, and their applications in the market will also continue to expand.

\section{Simulation Analysis}

Randomly located nodes are generated in a circle with a radius of $R$, and each node has a one-hop transmission distance of $r$, forming a network with a random topological structure, and there are no isolated nodes in the network. The initial time slot reference datum of each node is uniformly distributed in the interval $\left[0, T_{s}\right] . T_{s}$ is a time slot period. According to the parameters, the simulation is performed 150 times, and the algorithm is iterated 150 times in one simulation, and the normalized maximum time slot reference deviation value and the average value of the normalized maximum time slot adjustment value in the 150 simulations are calculated. The normalized maximum time slot deviation value is defined as the maximum time slot deviation value divided by a time slot period; the normalized maximum time slot adjustment is defined as the maximum time slot adjustment amount divided by a time slot period; the normalized coverage radius is defined as dividing the effective transmission distance of a node by $R$.

25 network nodes are set up; the normalized coverage radius of each e-commerce interaction is 0.5 , compared with mobile ad hoc distributed algorithms: other algorithm 1 and other algorithm 2 . The relationship between specific average time slot deviation and the number of iterations is shown in Figure 3.

From the results in Figure 3, the maximum time slot deviation value tends to decrease as the number of iterations increases. Therefore, it can be considered that the algorithm tends to converge. Meanwhile, by comparison, the convergence speed of the mobile ad hoc distributed algorithms in this paper is relatively faster. 


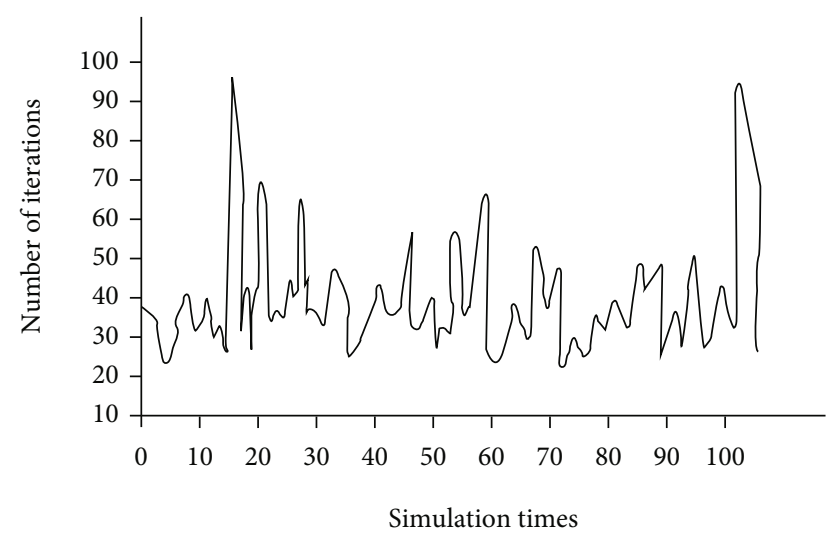

FIGURE 4: Number of iterations per simulation.

The number of iterations and average number of iterations for each simulation are further calculated, as shown in Figure 4.

It can be seen from the results in Figure 4 that the maximum time slot deviation can be reached after 37 iterations of the algorithm, and it tends to converge. According to the transmission relationship between the average number of iterations after the simulation and the normalization, as shown in Figure 5, it can be seen from the results in Figure 5 that the higher the radius of the coverage node, the larger the connectivity of each e-commerce interactive marketing, the smaller the maximum number of hops in the network, so the convergence speed is relatively improved.

When the mobile ad hoc distributed algorithms are simulated for 300 iterations, the relationship between the number of e-commerce interactive marketing nodes and the average number of iterations is shown in Figure 6.

It can be seen from the results that within the specific scope limit, the node coverage radius of e-commerce interactive marketing remains unchanged, and the maximum number of network hops hardly changes. As the degree of connectivity continues to increase, the speed of convergence has also increased.

In the 100 simulations of the algorithm, in the ecommerce interactive marketing model, the relationship between the average value of the maximum time slot deviation and the running time of the iterations is shown in Figure 7.

From the results in Figure 7, it can be seen that in the case of node movement in the e-commerce interactive marketing model, the time slot deviation and number of adjustments decrease with the increase of the number of iterations, the algorithm gradually converges, the interactive marketing becomes more and more accurate, and the nodes gradually synchronize; the simulation experiment proved the effectiveness of the mobile ad hoc network distributed algorithm.

\section{Application of Mobile E-Commerce Interactive Marketing Model in Different Industries}

6.1. Education and Training Industry. The application of mobile e-commerce in the education industry is different

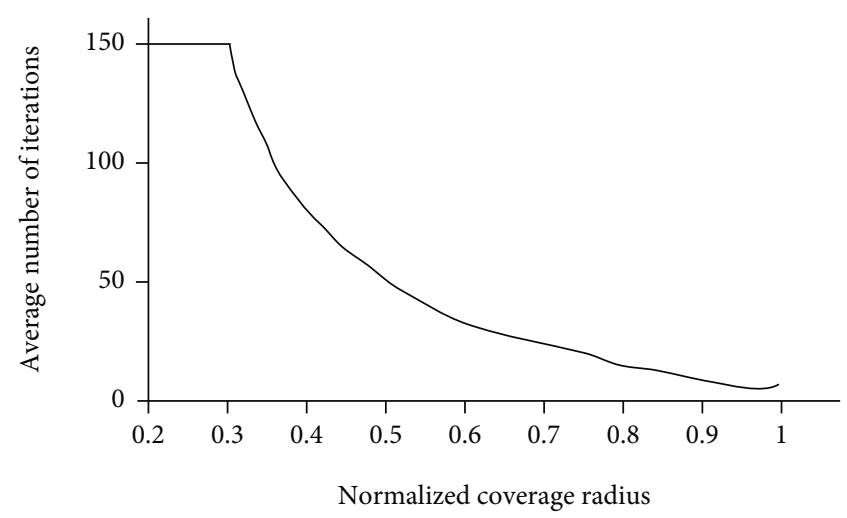

FIGURE 5: The relationship between the normalized coverage radius and the number of iterations.

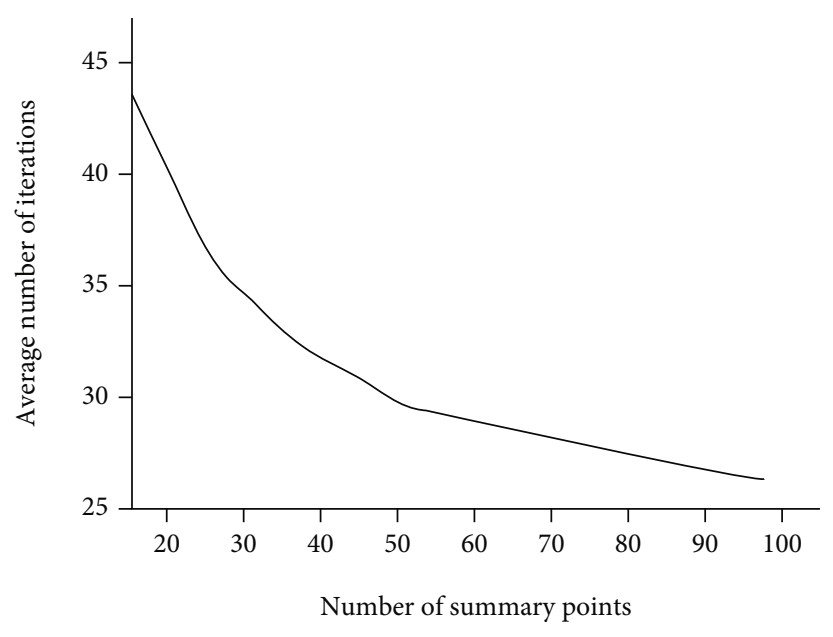

Figure 6: The relationship between the number of nodes and the number of iterations.

from other mobile e-commerce activities. Its activities must follow the laws of the education industry and provide added value for consumers who want to learn or receive education.

6.2. Tourism Industry. Travel marketing based on mobile ecommerce is the fastest marketing method, which can provide the fastest and most extensive personalized and self-service travel services.

6.3. Agriculture. The application of the mobile e-commerce interactive marketing model in agriculture not only makes the spread of agricultural product development and agricultural product supply and marketing information wider and better service and but also brings better opportunities for the production and sales of agricultural products in various regions.

6.4. Catering Service Industry. The mobile e-commerce interactive marketing platform can be used to provide the most interactive solutions for restaurant chains, catering services, gourmet operations, catering group purchases, and food orders. 


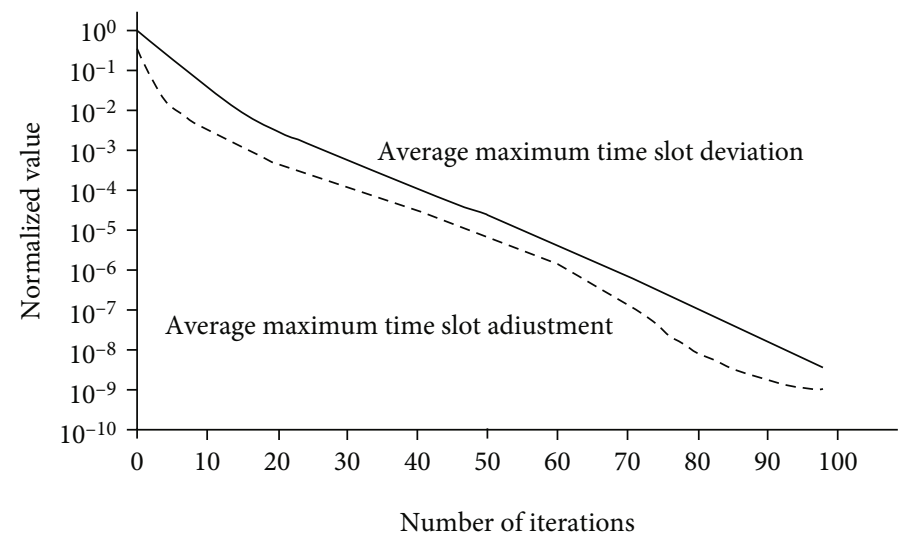

Figure 7: Convergence in the case of node movement.

6.5. Publication. Publishing houses use QR codes to upgrade from traditional print media to a new multimedia platform to achieve cross-media marketing and precision marketing; readers use QR codes to increase new channels for obtaining book information and generating purchase behavior and to achieve interaction with the publishing house.

\section{Conclusions}

With the continuous development of mobile smart terminals and Internet technology, e-commerce has gradually become one of the popular ways of consumption, but how to effectively and accurately conduct e-commerce transactions and obtain high-quality products with genuine products is a problem worthy of attention. The mobile ad hoc network distributed algorithm is introduced in this paper, through sorting out the process and methods of e-commerce interactive marketing, including mobile two-dimensional code, SMS address, and Weibo new media; conducting the electronic marketing in agriculture, tourism, and other many industries; further elaborating the effectiveness and necessity of e-commerce interactive marketing; and conducting simulation experiments. The experimental results show that the mobile ad hoc network distributed algorithm is effective and can satisfy the application of the e-commerce interactive marketing model.

\section{Data Availability}

Data sharing is not applicable to this article as no datasets were generated or analyzed during the current study.

\section{Conflicts of Interest}

The author declares no conflicts of interest.

\section{Acknowledgments}

This work was supported by the 2018 backbone teachers Training Program of Henan Colleges and Universities (No. 2018GGJS183).

\section{References}

[1] L. I. Wen-Xiu, "Research on rural tourism E-commerce marketing model innovation under the background of big data," DEStech Transactions on Social Science Education and Human Science, vol. 4, no. 3, pp. 1-9, 2017.

[2] Y. Kim and R. A. Peterson, "A meta-analysis of online trust relationships in E-commerce," Journal of Interactive Marketing, vol. 38, no. 5, pp. 44-54, 2017.

[3] G. Hod, S. A. H. Golpayegani, and M. Shahpasand, "A QoS sensitive model for e-commerce customer behavior," Journal of Research in Interactive Marketing, vol. 5, no. 7, pp. 109118, 2016.

[4] M. Y.-C. Yim, S.-C. Chu, and P. L. Sauer, "Is augmented reality technology an effective tool for E-commerce? An interactivity and vividness perspective," Journal of Interactive Marketing (Mergent, Inc.), vol. 39, no. 2, pp. 89-103, 2017.

[5] P. Liu and W. He, "Research on the E-commerce operation performance of SMEs based on cloud computing service platform," Revista de la Facultad de Ingenieria, vol. 32, no. 3, pp. 500-509, 2017.

[6] J. Wu, "An optimal design of relationship model between Ecommerce marketing and performance based on cloud service technology," Revista de la Facultad de Ingenieria, vol. 32, no. 9, pp. 540-547, 2017.

[7] A. Vohra and N. Bhardwaj, "Customer engagement in an ecommerce brand community," Journal of Research in Interactive Marketing, vol. 13, no. 1, pp. 2-25, 2019.

[8] Y. Wang and C. Yu, "Social interaction-based consumer decision-making model in social commerce: the role of word of mouth and observational learning," International Journal of Information Management, vol. 37, no. 3, pp. 179-189, 2017.

[9] E. Moriuchi, V. M. Landers, D. Colton, and N. Hair, "Engagement with chatbots versus augmented reality interactive technology in e-commerce," Journal of Strategic Marketing, vol. 29, no. 5, pp. 375-389, 2021.

[10] H. Bauer, C. M. Albrecht, M. M. Neumann, and T. E. Haber, "Enhancing customer trust in E-commerce through web portals," Revolution in Marketing: Market Driving Changes, vol. 6, no. 1, pp. 1-8, 2015.

[11] Y. Yusof, L. C. Hooi, and A. Abas, "User acceptance of QR code based mobile application in interactive E-commerce," Annals of Emerging Technologies in Computing, vol. 5, no. 5, pp. 102-107, 2021. 
[12] A. Wohllebe, T. Stoyke, and S. Podruzsik, "Incentives on Ecommerce app downloads in medium apps: a case study on the effects of coupons and bonus points," International Journal of Interactive Mobile Technologies (iJIM), vol. 14, no. 19, pp. 180-196, 2020.

[13] M. Teresa Ballestar, P. Grau-Carles, and J. Sainz, "Customer segmentation in e-commerce: applications to the cashback business model," Journal of Business Research, vol. 88, no. 7, pp. 407-414, 2017.

[14] M. Li and X. Zhang, "Information acquisition and its incentives in an E-commerce supply chain under the offline showroom model," Journal of Theoretical and Applied Electronic Commerce Research, vol. 16, no. 5, pp. 1791-1804, 2021.

[15] H. Jiang, "Analysis of the business model for promoting network interactive e-commerce," Agro Food Industry Hi-Tech, vol. 28, no. 1, pp. 1632-1636, 2017.

[16] S. Zhang, D. Zhang, H. Zhong, and G. Wang, "A multiclassification model of sentiment for E-commerce reviews," Access, vol. 8, no. 4, pp. 189513-189526, 2020.

[17] D. Reis, D. L. Vigorena, M. T. Kunzler, and P. S. Battisti, "Management practices in a long tail business model: a case study on e-commerce company," Espacios, vol. 4, no. 5, pp. 1-9, 2016.

[18] A. Alsaad, A. Taamneh, I. Sila, and H. Elrehail, "Understanding the global diffusion of B2B E-commerce (B2B EC): an integrated model," Journal of Information Technology, vol. 36, no. 3, pp. 258-274, 2021.

[19] P. Kumar and H. Kaur, "Determinants of e-commerce adoption: a literature-derived model for developing nations," International Journal of Business Information Systems, vol. 37, no. 2, pp. 182-190, 2021.

[20] F. Guo and Q. Lu, “A novel contextual information recommendation model and its application in e-commerce customer satisfaction management," Discrete Dynamics in Nature and Society, vol. 2015, Article ID 691781, 11 pages, 2015. 